\title{
The Role of Intellectual Capital and Tangible Resources on Competitive Advantages in Chinese High-tech Industry
}

\author{
Xianfeng Zhang ${ }^{1, a}$, Shenglei $\mathrm{Pi}^{2, b}$ \\ ${ }^{1}$ School of Business Administration South China University of Technology \\ Guangzhou, China \\ ${ }^{2}$ Institute of Industrial Economy and Enterprise Management Guangzhou Academy of \\ Social Science, Guangzhou, China \\ aemail:160150150@qq.com bemail: pishenglei@126.com
}

Keywords: intellectual Capital; Tangible resources; High-tech Industry; Competitive Actions; Knowledge Management

\begin{abstract}
This paper uses empirical research methods examines the association between Knowledge Management and competition of Chinese pharmaceutical firms, and reveals the mechanism of innovative and intellectual resources to competitive actions and performance of Chinese high-tech firms. This paper has come out a series of conclusions: 1) Chinese pharmaceutical firms have more perception to adopt normal but frequent competitive actions rather than highly innovative moves; 2) Tangible resources, rather than intellectual capital, is regarded as strategic resources, whose similarity have moderating effects between competitive actions and performance; 3) Similarity of tangible resources have negative effects between frequency of action and performance, but have positive effects between deviance and performance, which means a firm with the higher similarity in tangible resources will have more endeavors on innovation and adopt the deviance moves.
\end{abstract}

\section{Introduction}

The market value of Chinese pharmaceuticals is about USD 150 billion in 2014, and it has become the world's second largest market. Besides, the Chinese pharmaceutical firms are becoming a growing player in world. Many international pharmaceutical firms get into the Chinese pharmaceutical manufacturing industry through FDI (foreign direct investment).

However, Chinese pharmaceutical industry, which relates to the national safety and health, are highly controlled by the government. Bureaucratic and policies system make the Chinese pharmaceutical firms have little choice in technological and products innovation. Most of Chinese pharmaceutical firms, especially SOEs, prefer to producing large-scale medicines which are almost authorized in other countries, or modernizing the traditional Chinese medicines e.

These will bring Chinese pharmaceutical firms backwards to traditional manufacturing industry, rather than a high-tech one. Based on the testing data from Chinese successful pharmaceutical firms that are listed in the Chinese stock market, SSE and SZSE (Shanghai Stock Exchange and Shenzhen Stock Exchange), this paper, which listed attempts to analyze the competitive actions of Chinese pharmaceutical firms, its association with the strategic resources of firm, as well as the intellectual capital representing the innovative capabilities, or the tangible resources.

\section{Literature Review}

Competition Dynamics. Competition dynamics refers to "the process of interaction, in which the firm adopting a series of competitive actions responds from its competitors, and the response also brings more responses to the former firm(s)" [1]. According to the theories of competition dynamics, corporate strategies are dynamics. While choosing actions, a firm should consider the responses of its competitors. Therefore, the firms should attack with deviance competition to make competitors hard to respond. Competitive deviance refers to firm competitive behavior's combination difference and 
implementation with competitors in the same period and industry [2]. It is an extension of complex competitive behavior in the industrial dimension.

Researchers find that when firms compete in a way of strategic combination and enhance the behavior diversification in strategic combination, it is beneficial to obtain unique competitive advantages, making competitors unprepared and unable to respond [3]. However, there are few present researches involved with the issue that what kind of organizational model can help firms effectively launch diversified competitive behaviors. M. Chen and D. Miller (2015) considered that competitive dynamics along with five dimensions - aims of competition, mode of competing, roster of actors, action toolkit, and time horizon of interaction - that proved usefulness of contrasting the rivalries and competitive-cooperative modes with a new approach called relational competition [4].

Moreover, J. Luoma and J.A. Lamberg (2014) supported the view that intensifying competition favored an increasingly routinized rather than improvised approach to competition, as it allows the firm to rapidly capture the contested opportunities [5].

Intellectual Capital and Resources Similarity. Since the late 1990s, management professionals and researchers began to define the intellectual capital components (H-S-C, Human Capital, Structure Capital and Customer capital), and there had been no generally accepted definition or classification of intellectual capital [6]. Stewart (1997) defined intellectual capital simply as "packaged useful knowledge"[7]. Edvinsson and Malone (1997) enriched the definition to "knowledge that can be converted into value"[8]. Researchers, by case studies and empirical surveys, found out that acquiring intellectual capital could help to enhance capabilities of organizational learning and innovation.

Reed et al. (2006)[9] developed an IC-based theory that intellectual capital is en effective and efficient way to help firm achieve the added value, and have higher performance. Renato, Stefan and Robert (2014) considered that intellectual capital supported the knowledge-based view of the firm that explained the long-term differences in firm profitability, showed not only that all three factors (H-S-R) independently leading to the creation of intellectual capital but also, more importantly, their interaction. "We present implications for knowledge management theory and practice", and "knowledge assets critical to intellectual capital that may translate into sustained competitive advantage" [10]. T. Cater and B. Cater (2009) showed the research results, a differentiation advantage was positively affected by financial resources and all three components (H-S-R) of intellectual capital. In addition, both forms of competitive advantages positively influence a company's performance [11].

Thus intellectual capital is viewed as a strategic resource, and it is the foundation for the firm to gain competitive advantage and superior financial performance.

\section{Hypothesis}

Competitive action is a result of its advantages, not resources and capabilities, even though the former are based on the latter. Scholars of competitive dynamics believe that the more frequently a firm takes the competitive actions, the more aggressive it is in the competitive market. Besides, the more different the action adopted, the harder its competitor to respond. Therefore, the higher deviance makes firm easier to gain advantages and build boundary for that advantages.

H1a: Frequency of actions has positive influence on performance.

H1b: Competitive deviance has positive influence on performance.

According to Chen's (1996) theory, the strategic resources of two firms would prefer to attack and respond to each other based on the source similarity. If their strategic resources are highly similar, they do not prefer to start attacking and responding. However, if their strategic resources are not highly similar, it will be easy to start the actions between them. Therefore, researchers put forward this theory and test: 1) In the Chinese pharmaceutical industry, whether the intellectual capital or tangible resources are the strategic resources with similarity being sensitive to the competition and the performance; 2) whether resource similarity theory are reliable to decide the competitive actions, for 
example, a firm should frequently or differentially adopt actions based on the resources similarity to its competitors.

H2a: Similarity of intellectual capital has moderating effects on frequency of actions and performance.

$\mathrm{H} 2 \mathrm{~b}$ : Similarity of tangible resources has moderating effects on frequency of actions and performance.

H2c: Similarity of intellectual capital has moderating effects on competitive deviance and performance.

$\mathrm{H} 2 \mathrm{~d}$ : Similarity of tangible resources has moderating effects on competitive deviance and performance.

\section{Research Designs and Results}

Data Gathering. This paper applied content analysis [2] to gather and code the data about competitive actions and repertoire. This paper chooses 13 Chinese pharmaceutical firms listed in Shanghai or (and) Shenzhen stock market as samples. Data from their annual reports and media reports since 2001 to 2013 (totally 169 samples of each firm in each year) are gathered, coded, and analyzed. Following the former studies [3], this paper categorized competitive actions into 8 types: investment or merger, cooperation and allies, proposing new products, proposing new technology, opening new store or entering new market, changing organizational structure or marketing system, changing prices, and taking public relationship activities.

Variables and Equations. Dependent Variable: This paper chose ROA (Return on Assets) as the index of dependent variable and the performance.

Independent Variable: 1) Frequency of Action: this paper calculated the frequency of competitive action with different types each year in each pharmaceutical firms. 2) Competitive Deviance: according to the calculation method adopted by former researchers[4], this paper adopts the formula as follows:

$$
\text { deviance }=\sum_{i}\left(p_{i}-\overline{p_{i}}\right)^{2}
$$

Where ${ }^{p_{i}}$ represents the proportion of $\mathrm{i}$ types of competitive actions adopted by focused firms, while $\bar{p}_{i}$ represents the average proportion of these types of competitive actions adopted by all competitors in the whole industry.

Moderating Variables: 1) Intellectual Capital: This paper measured the intellectual capital with VAIC methods[12]. 2) Tangible resources: This paper gathered the tangible resources of each firm from their annual reports. Both intellectual capital and tangible resources are calculated as minus the average level of the 13 firms in particular years, as to be the similarity.

Control Variables: This paper chose the previous profit and resources slack as control variables, while resources slack is mainly measured by size, years of born, and the current ratio (proportion of current assets to current debts).

Analysis Results. This paper applied multiple linear regression models with SPSS 16.0. The analysis results are shown in Table 1 . From Table 1 , all models are significantly $\mathrm{F}$ tested, which means the regression models have good fitting degree. Moreover, Model 2ab and Model2cd have higher R square adjusted values than Model 1, meaning that all moderation effects are testified by the empirical analysis.

According to Model 1, Frequency $(\mathrm{FR})$ has significantly $(\mathrm{p}<0.05)$ positive effect on performance, thus $\mathrm{H1a}$ is accepted. However Deviance (DE) has significantly $(\mathrm{p}<0.05)$ negative effect on performance, thus H1b is rejected. According to Model 2ab, intellectual capital (IC) and FR don't have significant interacting effects on performance, thus $\mathrm{H} 2 \mathrm{a}$ is rejected, while tangible resources (TR) and FR have significantly $(\mathrm{p}<0.05)$ negative interacting effects on performance, it represents that $\mathrm{H} 2 \mathrm{~b}$ is 
accepted. Similarly in Model 2cd, intellectual capital (IC) and DE do not have significant interacting effects on performance, but the tangible resources (TR) and DE have significantly $(\mathrm{p}<0.05)$ negative interacting effects on performance, which means $\mathrm{H} 2 \mathrm{c}$ is rejected but $\mathrm{H} 2 \mathrm{~d}$ accepted.

Table 1 Multiple Linear Regression

\begin{tabular}{|c|c|c|c|}
\hline & Model1 & Model2ab & Model2cd \\
\hline (Constant) & $\begin{array}{l}.002 \\
(-.065) \\
\end{array}$ & $\begin{array}{l}.009 \\
(.761) \\
\end{array}$ & \begin{tabular}{|l}
.008 \\
$(.584)$ \\
\end{tabular} \\
\hline \multicolumn{4}{|l|}{ Control } \\
\hline Size & $\begin{array}{l}9.015 \mathrm{E}-7 \\
(.542) \\
\end{array}$ & $\begin{array}{l}9.390 \mathrm{E}-7 \\
(.828)\end{array}$ & $\begin{array}{l}4.802 \mathrm{E}-7 \\
(.419)\end{array}$ \\
\hline Previous Profit & $\begin{array}{l}7.335 \mathrm{E}-11 * * * \\
(5.031)\end{array}$ & $\begin{array}{l}1.147 \mathrm{E}-10 * * * \\
(8.468)\end{array}$ & $\begin{array}{l}1.162 \mathrm{E}-10^{* * *} \\
(8.604)\end{array}$ \\
\hline Year of Born & \begin{tabular}{|l|}
$8.718 \mathrm{E}-5$ \\
$(1.036)$ \\
\end{tabular} & $\begin{array}{l}000 \\
(1.673) \\
\end{array}$ & $\begin{array}{l}9.808 \mathrm{E}-5 \\
(1.687)\end{array}$ \\
\hline Current Ratio & \begin{tabular}{|l}
-.002 \\
$(-.789)$ \\
\end{tabular} & $\begin{array}{l}001 \\
. .226) \\
\end{array}$ & \begin{tabular}{|l}
.001 \\
$(.325)$ \\
\end{tabular} \\
\hline \multicolumn{4}{|l|}{ Independent } \\
\hline Frequency (FR) & $\begin{array}{l}340^{*} \\
(2.147) \\
\end{array}$ & $\begin{array}{l}144 \\
(1.808) \\
\end{array}$ & $\begin{array}{l}.002 \\
(1.580)\end{array}$ \\
\hline Deviance (DE) & $\begin{array}{l}.284^{*} \\
(-2.469)\end{array}$ & $\begin{array}{l}-140 \\
(-1.807) \\
\end{array}$ & $\begin{array}{l}028 \\
(1.130) \\
\end{array}$ \\
\hline \multicolumn{4}{|l|}{ Moderating Variable } \\
\hline Intellectual Capital(IC) & & $\begin{array}{l}.092 \\
.948) \\
\end{array}$ & \begin{tabular}{|l}
.253 \\
$(1.551)$ \\
\end{tabular} \\
\hline Tangible Resources (TR) & & $\begin{array}{l}043 \\
(.427) \\
\end{array}$ & \begin{tabular}{|l|}
-019 \\
$(-.218)$ \\
\end{tabular} \\
\hline \multicolumn{4}{|l|}{ Interaction } \\
\hline FR*IC & & $\begin{array}{l}.016 \\
(-.125) \\
\end{array}$ & \\
\hline FR*TR & & \begin{tabular}{|l|}
$.220^{*}$ \\
$(-1.984)$ \\
\end{tabular} & \\
\hline DE*IC & & & $\begin{array}{l}-.705 \\
(-1.407) \\
\end{array}$ \\
\hline DE*TR & & & $\begin{array}{l}.145^{*} \\
(-1.799) \\
\end{array}$ \\
\hline$R^{\wedge} 2$ & .353 & 367 & 364 \\
\hline $\mathrm{R}^{\wedge} 2$ adjusted & .273 & 326 & .323 \\
\hline$\Delta \mathrm{R}^{\wedge} 2$ adjusted & & .053 & .05 \\
\hline F value & $4.37^{* * * *}$ & $9.047 * * *$ & $8.912 * * *$ \\
\hline
\end{tabular}

*** Significant of regression is at the level of 0.001 (two-tail).

**. Significant of regression is at the level of 0.01 (two-tail)

*. Significant of regression is at the level of 0.05 (two-tail) 


\section{Summary}

This paper tests the influences of competitive actions on the Chinese pharmaceutical firms, and innovative or manufacturing resources are the most important ones in their competition. This paper has come out a series of conclusions: 1) Chinese pharmaceutical firms have more perception to adopt normal but frequent competitive actions rather than highly innovative moves; 2) tangible resources, rather than intellectual capital, is regarded as strategic resources, whose similarity have moderating effects on competitive actions and performance; 3) as Chen, similarity of tangible resources have negative effects on the frequency of action and performance, but have positive effects between deviance and performance, meaning if a firm has the higher similarity of tangible resources, it will have more endeavor on innovation and adopt deviance moves.

\section{Acknowledgment}

This work was financially supported by the Joint Project from Guangzhou Social Science and "Guangzhou Focus Research Base of Humanities and Social Science: The Word Famous Cultural City and Cultural Industry Research".

\section{References}

[1] Hunt, M., S. Competition in the Major Home Applicance Industry. Harvard University. 1972.

[2] Ndofor, H.A., D.G. Sirmon and X. He, "Firm Resources, Competitive Actions and PerformanceInvestigating a Mediated Model with Evidence from the In-vitro Diagnostics Industry", Strategic Management Journal, 31(6), pp. 640-657, 2011.

[3] Clemmons, Simon, "Control and Coordination in Global ERP Configuration", Business Process Management Journal, 7(3), pp. 205-215, 2001.

[4]M.Chen ,D.Miller. Reconceptualizing Competitive Dynamics: A Multidimensional Framework[J] Strategic Management Journal. May 2015 Volume 36, Issue 5, pages 758-775

[5] J.Luoma, J.A. Lamberg.Competitive Action Routines and Their Role in Interfirm Rivalry.[C] ACAD MANAGE PROC January 2014 ,2014 (Meeting Abstract Supplement) 10771

[6] OECD. Creating Value from Intellectual Assets[C], Meeting of the OECD Council at Ministerial Level. Paris. 2006.

[7] Stewart, T.A. Intellectual Capital: The New Wealth of Organisation[M]. Nicholas Brealey, London. 1997.

[8]Edvinsson, L. and Malone, M. Intellectual Capital: Realizing your Company's True Value by Finding its Hidden Brainpower[M]. Harper Collins, New York, NY. 1997.

[9] Reed, K.K., Lubatkin, M. and Srinivasan, N. Proposing and Testing an Intellectual Capital-based View of the Firm. Journal of Management Studies, 43(4), pp. 867-93, 2006.

[10] Renato S. Author Vitae, Stefan H.Author Vitae, Robert P. Measuring Intellectual Capital with Financial Figures: Can We Predict Firm Profitability? European Management Journal [J] Volume 32, Issue 2, April 2014, Pages 244-259

[11]T. Cater, B.Cater. (In)tangible Resources as Antecedents of a Company's Competitive Advantage and Performance [J]Journal for East European Management Studies, Vol. 14, No. 2, 2009

[12] Pulic A. Measuring the Performance of Intellectual Potential in Knowledge Economy (1988-). http:// www. Measuring-ip. At/Opapers/Pulic/Vaictxt. vaictxt. Html 